\title{
INFLUÊNCIA DA VAZÃO DE LÍQUIDO NA QUEDA DE PRESSÃO TOTAL E NA FORMAÇÃO DE ESPUMA EM UM PRATO DUAL FLOW
}

\author{
M. BRONDANI ${ }^{1}$, Y. S. SENGER ${ }^{1}$, F. D. MAYER ${ }^{1}$ e HOFFMANN, R. ${ }^{1}$ \\ ${ }^{1}$ Universidade Federal de Santa Maria, Departamento de Engenharia Química \\ E-mail para contato: mbbrondani@gmail.com
}

\begin{abstract}
RESUMO - A operacionalidade de pratos sem downcomer é comumente avaliada através de parâmetros fluidodinâmicos como a queda de pressão total no prato. Essa queda de pressão é dada em função da perda de carga ocasionada pela passagem da fase gasosa, pela retenção de líquido sobre o prato e pela observação da espuma sobre o prato, formada devido ao contato entre as fases. Este trabalho avaliou a queda de pressão total e a espuma formada em um prato dual flow a partir da variação da vazão volumétrica da fase líquida. Os resultados mostraram que a queda de pressão total foi menor na vazão de $300 \mathrm{~L} / \mathrm{h}$ e maior na vazão de $1200 \mathrm{~L} / \mathrm{h}$ e aumenta com o aumento da vazão volumétrica da fase gasosa em todas as vazões de líquido analisadas. No entanto, em baixas vazões de líquido (300 $\mathrm{L} / \mathrm{h})$ e gás $\left(118,8 \mathrm{~m}^{3} / \mathrm{h}\right)$ não ocorreu a formação de espuma sobre o prato e sob elevadas vazões de ar $\left(381,6 \mathrm{~m}^{3} / \mathrm{h}\right)$ e baixas de líquido $(300 \mathrm{~L} / \mathrm{h})$ a formação da espuma é fina e leve, podendo causar arraste da fase líquida. Sob baixas vazões de ar $\left(118,8 \mathrm{~m}^{3} / \mathrm{h}\right)$ e elevadas vazões de líquido $(1200 \mathrm{~L} / \mathrm{h})$ a espuma formada foi menos intensa em virtude da elevada quantidade de líquido. A espuma formada foi mais homogênea e uniforme em vazões intermediárias de líquido e gás, em especial em $900 \mathrm{~L} / \mathrm{h}$ e entre 237,6 e $288 \mathrm{~m}^{3} / \mathrm{h}$, respectivamente. Os resultados mostraram a importância da avaliação da queda de pressão total e espuma sobre a operacionalidade de pratos dual flow.
\end{abstract}

\section{INTRODUÇÃO}

Os pratos sem downcomer possuem fluxo em contracorrente, dessa forma, a fase líquido e vapor passam através da mesma abertura do prato. Segundo Mayer et al. (2014), os principais tipos de pratos sem downcomer são: Kittel, Ripple, Turbogrid e Dual flow.

O tipo de prato sem downcomer mais simples é o dual flow e constitui-se de uma chapa circular com furos circulares em arranjo triangular equilateral ou quadrado (Kister, 1992; Furzer, 2000; Jiang et al., 2013).

O funcionamento adequado de pratos sem downcomer é avaliado por meio de parâmetros fluidodinâmicos, sendo os principais, a altura de líquido e espuma sobre o prato, capacidade, eficiência e queda de pressão total (Mayer et al., 2014).

A queda de pressão total $(\Delta \mathrm{P})$ nos pratos é um importante parâmetro a ser considerado no projeto de uma coluna destilação, pois com a diminuição da pressão do sistema os pontos de ebulição das substâncias diminuem, facilitando assim a evaporação de compostos mais 
pesados e não desejados (Kister, 1992; Geankoplis, 2003). A espuma formada sobre o prato, em virtude do contato líquido-vapor, permite obter uma avaliação do efetivo contato entre as fases sobre o prato, além de ser a região onde ocorre a maior parte da transferência de massa entre as fases.

O objetivo desse estudo foi calcular a queda de pressão total e avaliar a formação de espuma em um prato sem downcomer do tipo dual flow, a partir da variação da vazão volumétrica de líquido.

\section{MATERIAIS E MÉTODOS}

Os resultados experimentais foram obtidos por meio de um protótipo representativo de uma coluna de pratos sem downcomer, instalado no Laboratório de Operações Unitárias da Universidade Federal de Santa Maria (UFSM), cujo esquema é mostrado na Figura 1.

O protótipo é constituído por um tubo cilíndrico de acrílico transparente de 1,0 metro de altura e 0,34 metro de diâmetro no qual são introduzidos os pratos na forma de cartucho.

Figura 1 - Protótipo representativo da coluna de destilação

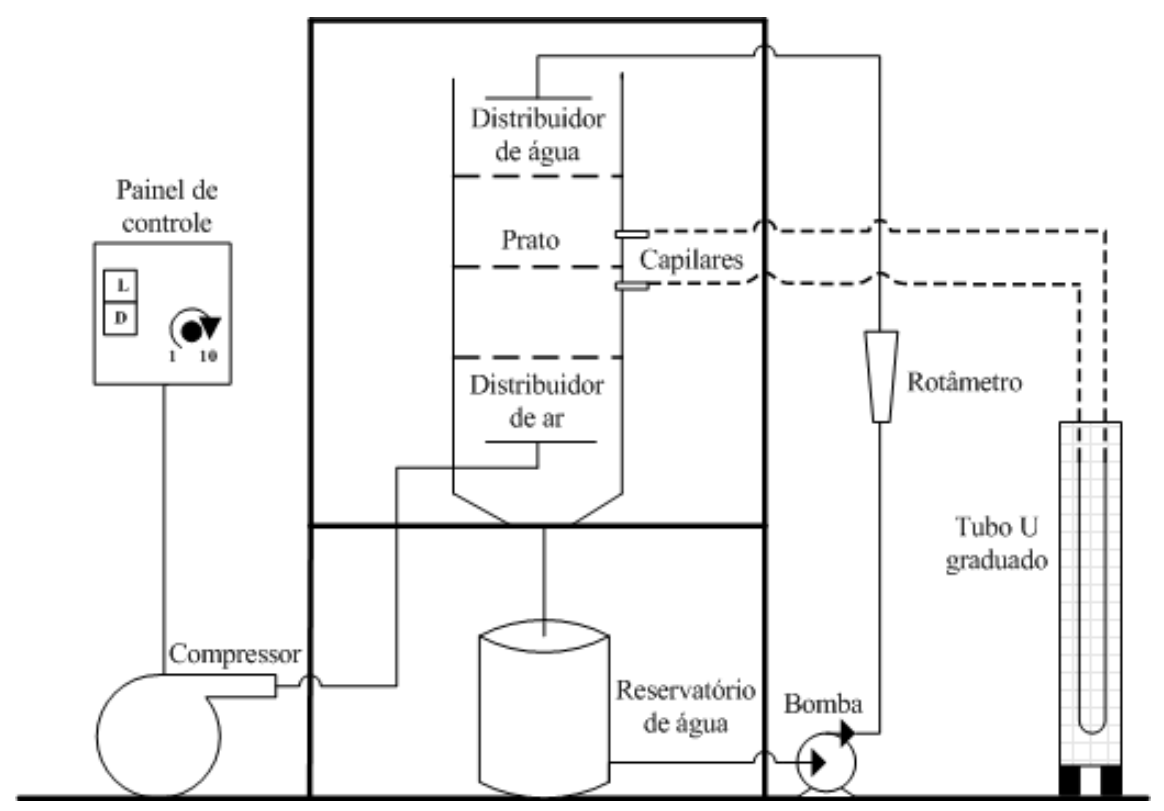

O sistema possui um compressor, cuja vazão de fase gasosa ou vapor (ar) é controlada por um painel de controle, e o ar é introduzido pela parte inferior da coluna, sendo orientado a ocupar uniformemente a área da seção transversal do prato através de um distribuidor de ar. 
A fase líquida (água) é introduzida na parte superior da coluna através de uma bomba, sendo coletado na parte inferior e armazenado em um recipiente, de aproximadamente $40 \mathrm{~L}$, para recirculação. A vazão de água é controlada por uma válvula e um rotâmetro, instalados na canalização de água. $\mathrm{O}$ ar e a água passam através dos três pratos, sendo o prato central escolhido para coleta de dados da queda de pressão total e visualização da formação de espuma. Por outro lado, os pratos das extremidades auxiliam na distribuição uniforme do ar e da água sobre o prato central.

A queda de pressão total foi calculada através da Equação 1, a partir da variação da altura de líquido (água) de um manômetro U graduado, conectado acima e abaixo do prato central. A observação da espuma ocorreu de maneira visual através da coluna de acrílico transparente.

$\Delta \mathrm{P}=\rho_{\text {água }} \cdot \mathrm{g} \cdot \mathrm{h}$

Onde $\Delta \mathrm{P}$ é a queda de pressão total $(\mathrm{Pa}), \rho_{\text {água }}$ é a densidade do fluido manométrico (água, $\left.997 \mathrm{~kg} / \mathrm{m}^{3}\right)$, g é a aceleração da gravidade $\left(9,81 \mathrm{~m} / \mathrm{s}^{2}\right)$ e $\mathrm{h}$ é a altura de líquido deslocado no manômetro $\mathrm{U}(\mathrm{m})$.

Foram variadas 4 vazões de líquido $(300,600,900$ e $1200 \mathrm{~L} / \mathrm{h})$ e avaliado sua influência na queda de pressão total do prato e na formação de espuma no prato. As vazões volumétricas da fase gasosa ou vapor $\left(\mathrm{W}_{\mathrm{ar}}\right)$ usadas foram 118,$8 ; 174,6 ; 237,6 ; 288$ e $381,6 \mathrm{~m}^{3} / \mathrm{h}$.

A Figura 2 mostra os 3 pratos introduzidos na forma de cartucho e vedados em sua circunferência para evitar vazamento pelas paredes da coluna. Os pratos possuem $0,34 \mathrm{~m}$ de diâmetro e $0,002 \mathrm{~m}$ de espessura, com furos de $0,005 \mathrm{~m}$ de diâmetro em arranjo triangular equilateral com passo de $0,01063 \mathrm{~m}$ entre eles. Os pratos estão espaçados a uma distância de $0,18 \mathrm{~m}$ e possuem área livre de $19,75 \%$.

Figura 2 - Cartucho de pratos dual flow

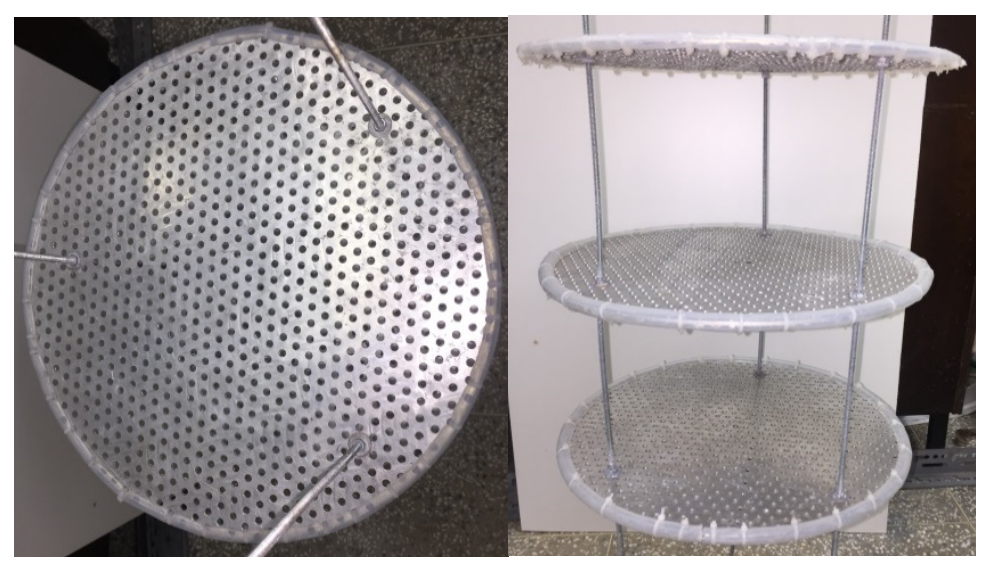




\section{RESULTADOS E DISCUSSÃO}

Os resultados mostraram que a queda de pressão total eleva-se com o aumento da vazão volumétrica de ar e água. A medida que a vazão de ar aumenta, mais elevada é a queda de pressão total no prato, pois maior a quantidade da fase gasosa a passar pelo prato e mais intensa é a resistência do prato a sua passagem.

Além disso, a medida que a vazão volumétrica da fase líquida aumenta, mais elevada é a queda de pressão total no prato, pois maior é a quantidade de líquido retido sobre o prato.

A Figura 3 mostra os resultados da queda de pressão total em função da variação da vazão volumétrica de ar e água.

Figura 3 - Queda de pressão total função da vazão volumétrica de líquido e ar

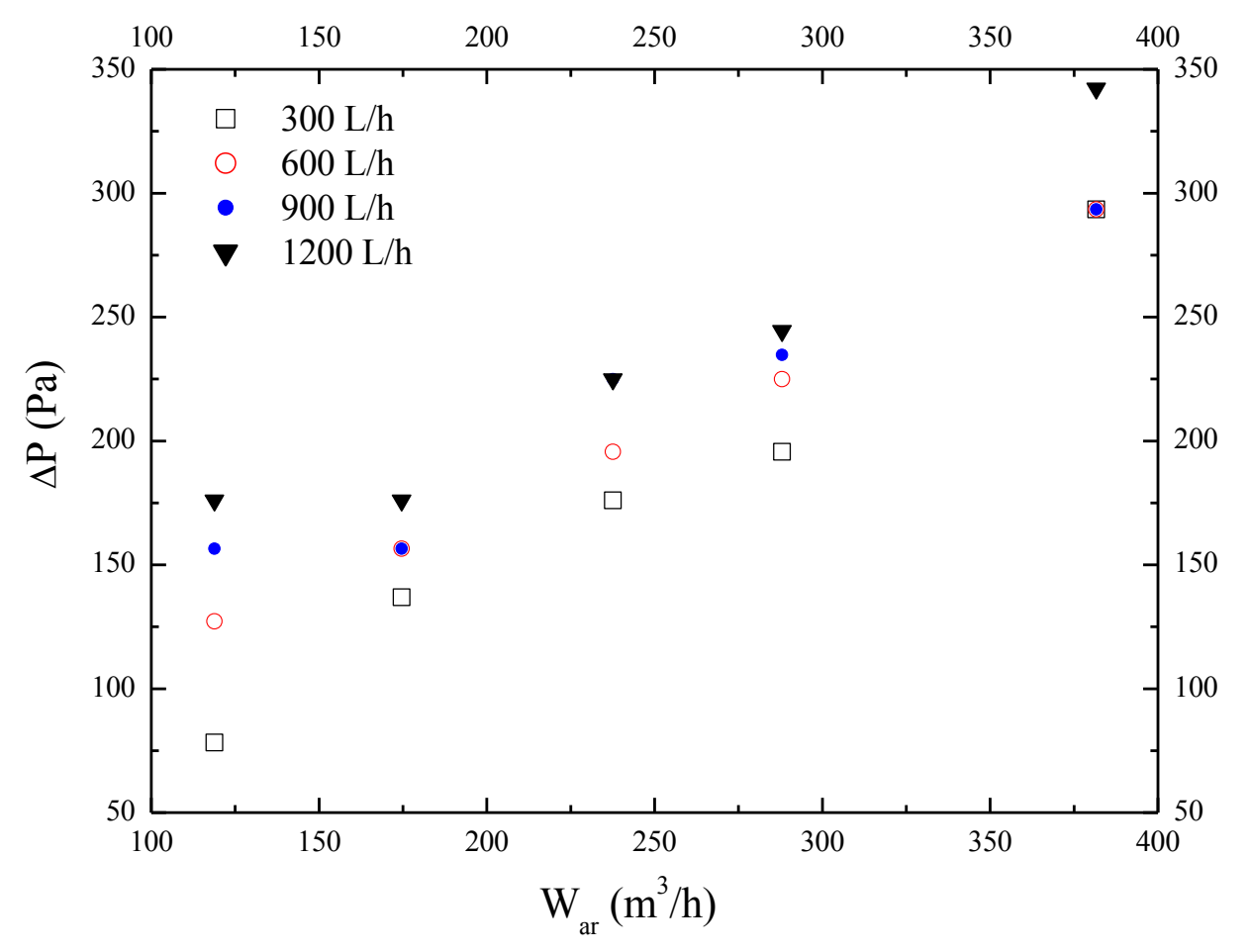

Os resultados mostrados na Figura 3 indicaram que a queda de pressão total foi menor na vazão de $300 \mathrm{~L} / \mathrm{h}$ e maior na vazão de $1200 \mathrm{~L} / \mathrm{h}$.

Com relação a formação de espuma sobre o prato, observou-se que na vazão de ar igual a $118,8 \mathrm{~m}^{3} / \mathrm{h}$ e $300 \mathrm{~L} / \mathrm{h}$ de água, não houve formação de espuma sobre o prato, formando apenas uma fina camada de líquido e, portanto, o contato entre as fases é "pobre". Nas demais vazões de líquido e gás houve formação de espuma, sendo mais intensa sobre altas vazões gás, fato explicado pela elevada capacidade do ar em sustentar a camada de líquido sobre o prato e com intenso contato entre as fases. 
No entanto, sobre altas vazões de ar e baixas de líquido, houve a formação de uma camada de espuma espessa, mas com gotículas muito finas, o que pode resultar em arraste da fase líquida.

Dessa forma, em vazões intermediárias de ar $\left(237,6\right.$ e $\left.288 \mathrm{~m}^{3} / \mathrm{h}\right)$ e sobre vazão de 900 $\mathrm{L} / \mathrm{h}$ houve uma aparente tendência à estabilização da queda de pressão, ainda que superior às vazões de 300 e $600 \mathrm{~L} / \mathrm{h}$, no entanto, com formação de uma espuma mais uniforme e uma operacionalidade mais estável.

A Figura 4 mostra os principais resultados da formação de espuma de acordo com a variação da vazão volumétrica de líquido e gás.

Figura 4 - Espuma formada sobre o prato

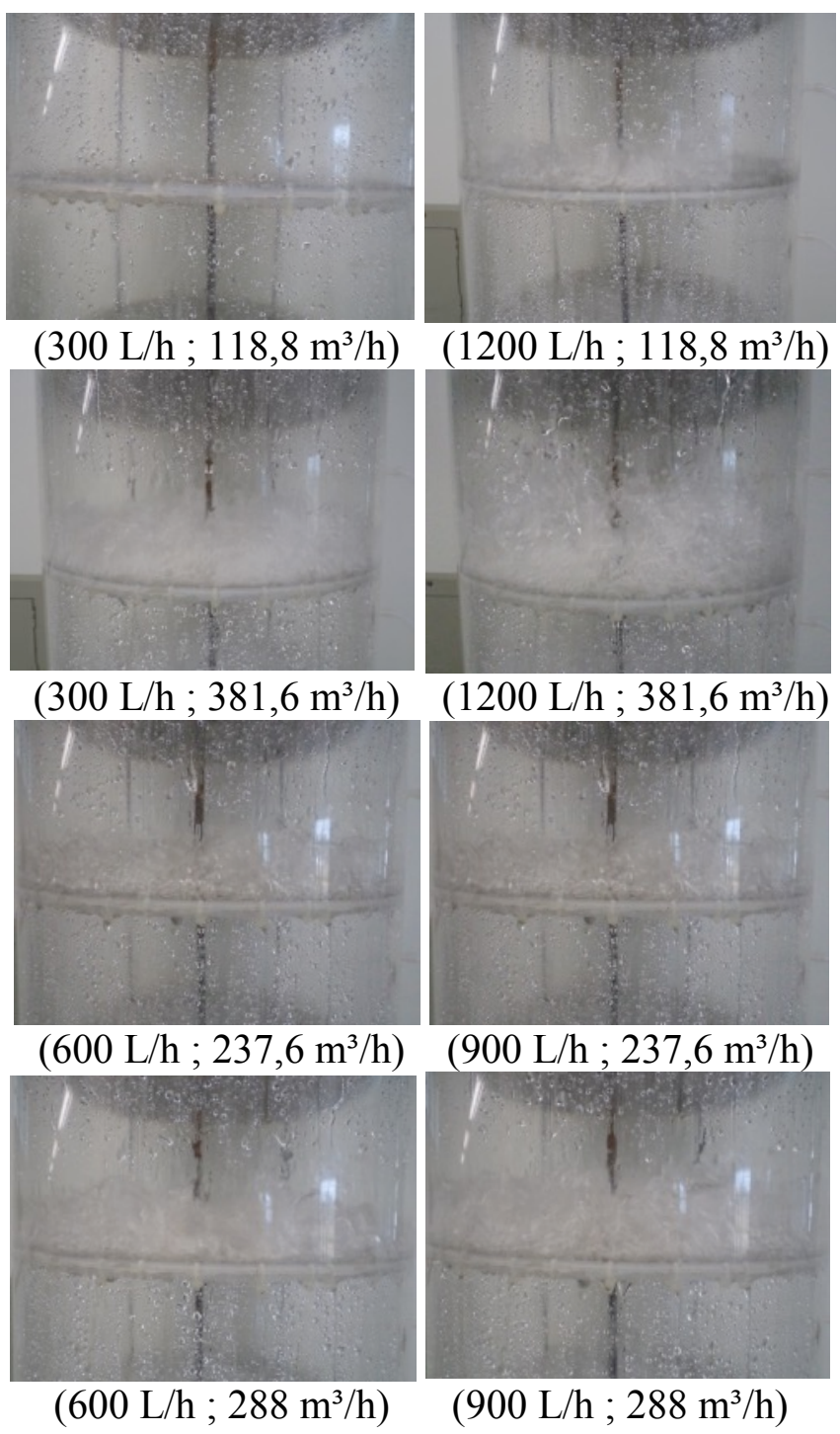




\section{CONCLUSÃO}

Os resultados desse estudo comprovaram que a vazão de líquido influencia na queda de pressão total e na formação da espuma em pratos dual flow. A queda de pressão total foi mais elevada na vazão de $1200 \mathrm{~L} / \mathrm{h}$ e menor na vazão de $300 \mathrm{~L} / \mathrm{h}$ e a formação de espuma sobre o prato nessas vazões foi desfavorável à operacionalidade do processo.

Conclui-se que as condições mais adequadas de operação da coluna foram na vazão de água de $900 \mathrm{~L} / \mathrm{h}$ e com vazão de ar entre 237,6 e $288 \mathrm{~m}^{3} / \mathrm{h}$. Isso se deve ao fato de que a espuma formada sobre o prato se mostrou mais uniforme e consistente e a queda de pressão total tem a tendência a se manter constante entre essas vazões de ar.

\section{REFERÊNCIAS}

FURZER, I. A. Froth Heights on Dualflow Trays with a Ternary Azeotropic System of Ethyl Acetate-Ethanol-Water. Ind. Eng. Chem. Res., vol. 39, p. 1430-1436, 2000.

GEANKOPLIS, C. J. Transport Processes and Separation Process Principles. Editora Prentice Hall, $4^{\circ}$ Ed., 2003.1026 p.

JIANG, B.; LIU, P.; ZHANG, L.; SUN, Y.; WANG, H.; LIU, Y.; FANG, Z. Hydrodynamics and mass-transfer analysis of a distillation Ripple tray by computational fluid dynamics simulation. Ind. Eng. Chem. Res., vol. 52, p. 17618-17626, 2013.

KISTER, H. Z. Distillation Design. Editora McGraw-Hill, 1992. 710 p.

LOCKETT, M. J. Distillation tray fundamentals. Editora Cambridge University Press, 1986. $226 \mathrm{p}$.

MAYER, F. D.; FERIS, L. A.; MARCILIO, N. R.; BALDO, V.; HOFFMANN, R. Review of Hydraulics Correlations for Sieve Trays without Downcomers. Ind. Eng. Chem. Res., vol. 53, p. 8323-8331, 2014. 